\title{
Orientation of drill core by use of borehole geophysical imaging
}

\section{Technical Notes}

S.F. Rogers, D.E. Bailey \& A. Kingdon

Applied Earth Science: Transactions of the Institutions of Mining and Metallurgy: Section B

Volume 109, Issue 3, 2000, pages 184-190

DOI:10.1179/aes.2000.109.3.184

\begin{abstract}
Borehole core must be orientated relative to a geographic coordinate system if meaningful geological, structural and geotechnical information is to be derived from it. This can be achieved by matching core features with features revealed by geophysical images of the borehole wall. The orientation of a reference line marked on the drill core can thereby be calculated, along with the dip and azimuth of any significant features found in the core. A technique developed by the British Geological Survey (BGS) on the basis of borehole imaging is described here and evaluated in the light of results obtained in the orientation of core extracted on behalf of United Kingdom Nirex, Ltd (Nirex).
\end{abstract}

